\title{
Ciência e teatro A situação presente
}

\section{Eva-Sabine Zehelein}

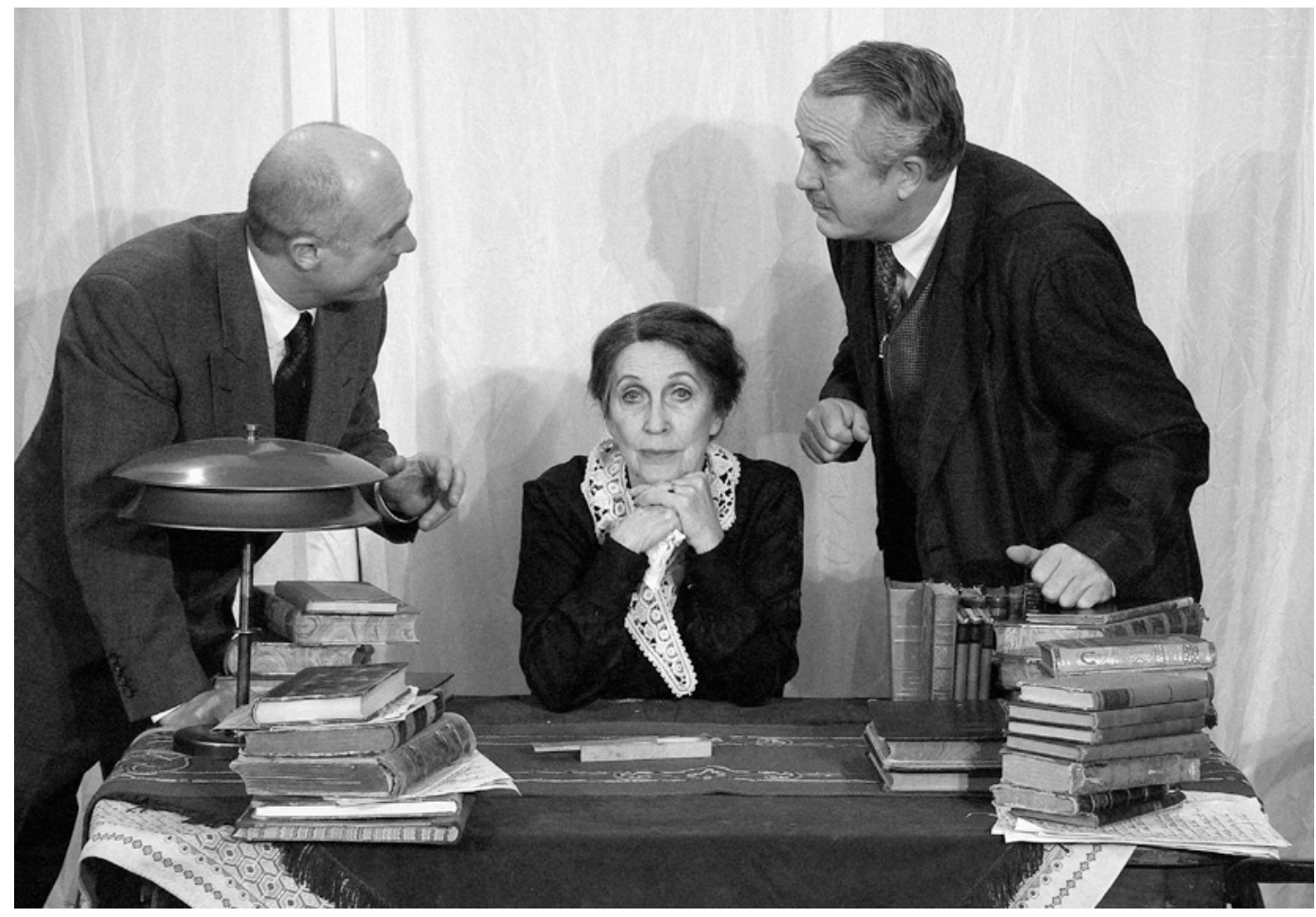

No artigo "The scientist on the stage [0 cientista em palco] " (2002), M. A. Orthofer constatou que uma "noção de incompatibilidade entre ciência e teatro continua muito enraizada" (Orthofer 2002: 173, tradução nossa). Outros observadores da cena teatral, como Carol Rocamora, perceberam que a "ciência é hoje o aspecto mais polémico do teatro, razão pela qual se tornou um fenómeno do milénio nos palcos anglófonos" (Rocamora 2000: 50, t.n.). Indo ao encontro da observação de Rocamora, este artigo defende que as "peças sobre a ciência" ${ }^{1}$ constituem um sub-género dramático distinto que reconheceu as ciências naturais como área cuja exploração se torna muito compensadora tanto em temas como em formas, fornecendo novas oportunidades de associar a expressão artística à pertinência social.

Em palco, a "peça sobre a ciência", depois de 1990, foi popularizada, em primeiro lugar, por Arcádia de Tom Stoppard, recebendo um segundo impulso com Copenhagen [Copenhaga] de Michael Frayn. 0 êxito comercial destas peças, da autoria de famosos e conceituados dramaturgos, pode ser uma explicação para o facto de as "peças sobre a ciência" passarem a ter uma maior visibilidade nos palcos comerciais e para que muitos outros textos viessem a ser publicados depois delas. Contudo, há também uma mão invisível do mercado que tem de ser mencionada, ainda que não possamos fazer aqui uma análise mais detalhada: instituições académicas e de investigação como a Alfred P. Sloan Foundation encorajaram os dramaturgos - através de bolsas e prémios - a entrar no campo científico ${ }^{2}$. 0 objectivo geral é ter cada vez mais pessoas envolvidas nas ciências e o objectivo subjacente é certamente corrigir a imagem negativa dessas ciências. Como resultado de conflitos militares tão devastadores como as Guerras Mundiais ou o Vietname, ou as crises ecológicas como, por exemplo, os acidentes nucleares na americana Three Mile Island (1979) ou na russa Chernobyl (1986) ou ainda na Fukushima japonesa (2011), a imagem da ciência e dos seus profissionais atingiu recordes baixissimos com repercussões a longo prazo. A ovelha clonada "Dolly" alertou o público para o progresso científico, mas também para os desenvolvimentos e consequências futuras dessas tecnologias. A clonagem coloca questões éticas sobre a natureza e o futuro do Homem e faz reviver a imagem do cientista como um Frankenstein moderno. No campo da Medicina, um trauma sério foi causado também, em 1960, pelo escândalo
Remembering Miss Meitner, de Robert Marc Friedman, Gothenburg City Theatre, 2002 (Johan Karlberg [Manne Siegbahn], Inger Hayman [Lise Meitner] e Ingemar Carlehed [Otto Hahn]), fot. Arturo Hernandez.

Sobre o uso do termo"peças sobre a ciência", ver Eva-Sabine Zehelein (2009).

Para mais informação sobre a Sloan Foundation ver: http://.sloan.org/mais.sh tml (data de acesso: 25 de Setembro de 2011).

Eva-Sabine Zehelein é professora de estudo anglo-americanos na Universidade de Bona. É autora de uma obra extensa dedicada à relação entre teatro e ciência. Publicou em 2009 o volume intitulado Science/Dramatic. Science Plays in America and Great Britain (1990-2007). 
${ }^{3} \mathrm{Cf}$. por exemplo, os geneticistas Bodmer

(1985), Priest (1995), ou Gregory/Miller (1998)

${ }^{4}$ John Carey, principal crítico literário do Sunda

Times e professor de

Literatura Inglesa, referiu

também um aspecto

importante em artigo não

assinado "O romance aproxima-se da ciência",

a 1 de Novembro de 2002

http://physicsworld.com cws/article/print/11362 [acedido a 7 de Julho de

2009]). Não quero especular sobre o papel e a influência da indústria

do livro na criação

perpetuação das

tendências literárias e n definição da sua agenda.

Referência à palestra "Two Cultures [Duas culturas]" (1959) - e

posterior publicação (1960; reeditada em 1960,

1993 e 2001 pela

Cambridge University Press) - do cientista romancista britânico C.P.

Snow que assim se referia

à separação, na cultura

ocidental, entre as

Ciências e as

Humanidades. (N.T)
"Contergan", como é conhecido na Alemanha, ligado ao composto Talidomida usado em mulheres grávidas para evitar os enjoos matinais e de que resultaram malformações nos fetos.

Como resultado destes e de outros acidentes extremamente prejudiciais, perigosos e traumatizantes, muitas instituições e fundações viram-se na necessidade de se tornarem "agentes de Relações Públicas" de forma a corrigirem a visão da ciência, mas também a estabelecerem uma comunicação entre as torres de marfim dos cientistas e o público. 0 objectivo final é sempre a informação a fim de esbater os medos irracionais e a ansiedade. Contudo, essas instituições que apoiam o Entendimento Público da Ciência ${ }^{3}$, ou Gregory/Miller (1998). representam também muitas vezes - e isso pode ser entendido como o outro lado da moeda - uma porta aberta para a criação de obras dramáticas. Não devemos deixar, ainda, de ter em vista o facto de as suas escolhas terem uma função de definição programática e poderem constituir um factor decisivo para o êxito comercial de uma peça ou, pelo menos, para o seu reconhecimento público.

Os avanços científicos podem não só conduzir a interpretações artísticas, no mínimo, de "leitura fácil" e problematizações do mesmo tipo, mas também a reavaliações do passado. Podem despoletar novos debates sobre a relação entre a ciência e a sociedade em geral, e sobre as características idiossincráticas da ciência e dos seus praticantes. A História da Ciência, por exemplo, abrese, em muitos casos, a novas e inspiradas perspectivas, aquando da divulgação ou publicação de documentos (classificados), que suscitam reavaliações históricas e geográficas das personae e dos factos: por exemplo a conversa mantida na peça de Frayn Copenhaga. A investigação biográfica de cientistas eminentes (re)abriu frequentemente discussões sobre as suas posições políticas dentro dos respectivos contextos históricos, e conduziu a reavaliações do passado de uma nação e das suas responsabilidades históricas. Biografias recentes sobre J. Robert Oppenheimer, Werner Heisenberg, ou Albert Einstein - para referir apenas algumas - lançaram mais uma luz sobre o Projecto Manhattan, sobre o papel que os americanos e alemães desempenharam na génese da bomba atómica, e sobre as responsabilidades pessoais da pesquisa feita sob o seu patrocínio, muitas vezes iniciada mesmo pelos governos de cada país com fins militares e políticos. A História das realizações científicas levadas a cabo por mulheres foi corrigida depois de décadas de negação, deturpações e negligência tanto dos colegas como dos historiadores. Cientistas extraordinariamente dotadas como Rosalind Franklin ou Lise Meitner só postumamente foram reconhecidas pelas suas notáveis contribuições

Em terceiro lugar, histórias comoventes dominaram a Galáxia Gutenberg durante tempo demais. 0 poder apelativo da "escrita da ciência" - tanto em forma ficciona como em publicações científicas de divulgação, em pesquisa histórica ou em narrativas biográficas - atingiu a exaustão e o cansaço, depois de anos de desalento pós-moderno, ou de teatro pós-dramatico, que tantas vezes se banhou na lama do reducionismo, focando-se apenas nas emoções e problemas individuais num mundo fragmentado. Martin Esslin criticou com razão o moderno teatro (americano) por ser demasiado limitado nas suas temáticas. De forma jocosa ele postula que "muita escrita dramática para o palco pode ser vista meramente como uma continuação das novelas num plano ligeiramente superior" (Esslin 1988 23, t.n.). De acordo com Esslin, as familias disfuncionais e as categorias psicológicas individuais são de tal forma impositivas que o elemento político ou de crítica social do teatro foi empurrado para fora dos palcos" (Ibid., t.n.) E este é precisamente o fosso passivel de ser preenchido pelas peças sobre ciência na sua relevância social. Dramaturgos e escritores detectaram um interesse público nessas matérias e os seus trabalhos reflectem a consciência de que a ciência é agora o domínio do conhecimento para o século XXI, e de tal forma que os romancistas e dramaturgos "não querem estar, ou parecer estar, excluidos dele" ${ }^{4}$

Muitos romances, contos e peças de teatro trazem ao debate público as questões éticas da responsabilidade individual. Lançam, assim, novas luzes sobre a delicada relação entre cientistas, políticos, militares e público, e parece provado que o palco é o espaço mais indicado para este debate.

\section{Em defesa do texto dramático: o dilema terminológico e as novas categorias}

0 que diferencia claramente a tábua dura do palco da página narrativa são as particularidades do teatro, que, literalmente, oferece espaço para a magia de um affaire amoroso com as ciências naturais, possibilitando o estabelecimento de pontes entre as "duas culturas" Reconhecendo tanto os aspectos interdisciplinares como os transculturais das peças que envolvem as ciências naturais, alguns estudiosos aventuraram-se recentemente na demarcação e definição de "peças sobre a ciência" como um novo género dramático. Por enquanto, "peças sobre a ciência" funciona como uma designação abrangente e de amplo espectro.

Em vez de tentar definir as "melhores" ou mais emblemáticas "peças sobre a ciência", quero esclarece que estas peças tentam, em geral, fundir o campo da expressão artística num palco com o campo da "análise objectiva" e da pesquisa tanto no laboratório como no papel. Estas peças juntam duas áreas que, de acordo com o paradigma das "duas culturas", são inconciliáveis. Sempre que as peças sobre a ciência fazem uma negociação entre o plano da ciência e o da sociedade, elas atingem bons resultados na superação do fosso entre as "duas culturas", oferecendo explicações sobre a comunidade científica, elucidando contextos científicos, esclarecendo as ramificações políticas, sociais, éticas ou culturais da 


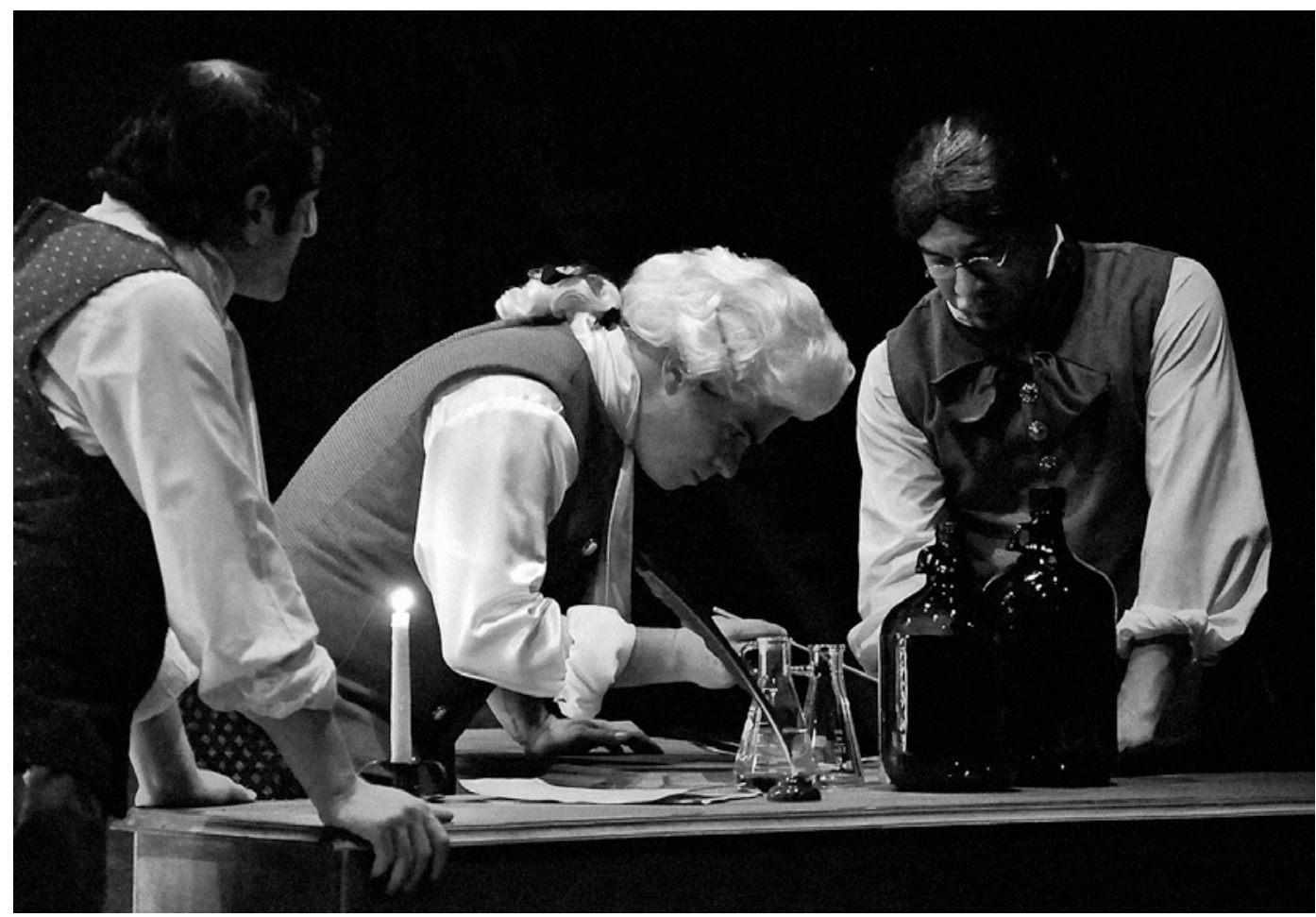

pesquisa e da descoberta científicas. Isto é conseguido não necessariamente através da definição do que elas implicam e significam a nivel perfomativo, mas, e vale a pena enfatizar este ponto, é o texto dramático, e não o espectáculo, que caracteriza as "peças sobre a ciência". É nos diálogos e nas palavras ditas que estas peças resolvem o seu argumento e sentido, proporcionando um tratamento mais discursivo dos seus temas. Para que a ciência ou os cientistas possam "funcionar" em palco, apresentando a sua mensagem, a palavra é necessária a um nível muito mais fundamental que a actuação. As "peças sobre a ciência" conseguem isto em vários formatos mas, em todos os casos, é obrigatória a presença da ciência, ou pelo menos uma dose elevada dela, o que as distingue da fiç̧ão científica.

\section{A ciência no teatro: "Docere et delectare" e "a comunidade tribal"}

Carl Djerassi criou a designação muito útil de "ciência no teatro", que inclui quatro elementos constitutivos: primeiro, uma fina descrição e representação da ideia ou assunto científico; segundo, uma representação realista da cultura tribal dos cientistas; terceiro, um enredo que esteja firmemente enraizado em questões e/ou contextos científicos; por fim, um elemento didáctico. A minha análise de mais de sessenta peças revelou que um ou outro destes elementos tende a predominar, de forma que se postulam aqui duas subdivisões de ciência no teatro.

"Docere et delectare": as peças estão concentradas numa questão científica que está a ser explicada didacticamente e "ensinada", como por exemplo, ICSI ou "neurologia 101". Dramaturgos como Djerassi sublinham repetidamente que desejam informar sobre "factos", fornecendo o conhecimento anterior primeiro e, depois, colocando questões sem, contudo, fornecerem respostas. 0 didactismo explícito de peças como Immaculate Misconception [Incompreensão Imaculada] (Djerassi 2000) ou On Ego [Ego] (Gordon / Broks 2005) dão origem ao forte desejo dos dramaturgos de fornecerem primeiro informação e conhecimento e só depois levantarem questões políticas ou éticas. Eles respondem a temas e discursos correntes, oferecendo o espaço do teatro para uma (re)negociação conjunta do (auto)conhecimento cultural, bem como para a discussão de posições privadas e políticas públicas. Estas peças analisam o aqui e agora, com um olhar dirigido ao futuro, mais do que ao passado, bem como o potencial desenvolvimento da pesquisa científica, as respectivas consequências para a sociedade e para o mundo em geral e o modo como as nossas vidas serão vividas.

A segunda sub-categoria, muito abrangente, pode ser intitulada "A cultura tribal dos cientistas no seu tempo e agora". "Cultura tribal" não deve ser mal interpretada como sendo uma apropriação antropológica da comunidade cientifica e/ou das obras dramáticas em discussão. 0 que o termo significa neste contexto é a representação dos mecanismos que operam no interior de uma comunidade científica - distinta de outros grupos sociais -,e que são frequentemente incompreensiveis ou francamente invisiveis para quem os observa de fora. Como interagem os cientistas das ciências naturais? 0 que determina os seus pensamentos e acções, como entendem a sua responsabilidade e posição na sociedade? Que regras regem a comunidade cientifica? Qual é o papel do êxito e como é definido? Por outras palavras: o que move os cientistas? Um exemplo paradigmático é Oxygen [Oxigénio], de Djerassi e Hoffmann. Através de duas linhas temporais, os autores mostram que o comportamento comum dos cientistas, a luta pela primazia e reconhecimento são idênticos em 1777 e em 2001. Outros dramaturgos olham para a relação entre a ética moral e o eros científico em geral, como é o caso de An Experiment With an Air Pump [Uma experiência com a bomba de ar] de Shelagh Stephenson, ou para a responsabilidade ética 
${ }^{6}$ Expressão latina que significa"0 que era preciso demonstrar" (NT).

${ }^{7}$ Ver o simpósio dos Arquivos de Niels Bohr em Copenhagen, 23 de Setembro de 2001 www.nbi.dk/NBA/files/se $\mathrm{m} / \mathrm{symp} / \mathrm{hitemore}$.htm [data de acesso: 25 de

Setembro de 2011].

Hitemore sublinha que tentou usar a matemática

como uma metáfora, não o enredo como uma ferramenta didáctica Para

uma representação dramática mais recente de Alan Turing ver Love Song of the Electric Bear

[A canção de amor do urso eléctricol de Snoo Wilson. de cientistas como Fritz Haber ou Albert Einstein em particular. Uma experiência com a bomba de ar apresenta diferentes facetas do cientista. Em 1799, entusiasmado pelo pensamento iluminista, o cientista analítico e mais humano colide com uma história de traição e de perda de esperança. 0 médico Fenwick acredita que o coração tem de fazer parte do labor científico, enquanto o seu colega Armstrong se mostra indiferente aos sentimentos. Ele brinca com as emoções da empregada Isobel e, de forma calculada, anestesia-a para poder observar a sua deformidade física. Na narrativa paralela, em 1999, Ellen decide continuar a sua carreira na engenharia genética devido ao fascínio e paixão pelo seu trabalho científico, e engole os escrúpulos éticos expressos por "Geordie builder Phil" e pelo seu marido, um professor de inglês desempregado. Tanto Oxigénio como Experiência usam diferentes linhas temporais nos seus respectivos enredos, tendo como objectivo uma comparação entre o "então" e o "agora". Em Oxigénio, as manobras internas do comite Nobel 2001 espelham as manigâncias dos cientistas do século XVIII e das suas mulheres, contrariando a crença ingénua sobre a integridade do trabalho científico. Em Experiência, os mesmos problemas são debatidos em 1799 e 1999: a natureza e o futuro do progresso, a conflituosa conditio humana tendo em vista a determinação do homem em "descodificar" a natureza e os problemas éticos que dai resultam. Uma experiência com a bomba de ar mostra como as consequências éticas do progresso, exemplificadas através do campo da Biologia, são aqui o "ponto quente" da engenharia genética. No âmago de uma teia simbólica muito complexa, reside a dicotomia entre a ética moral e a racionalidade científica que permanecem como uma constante nas nossas vidas desde neste caso em especial, 1799. Einstein's Gift [0 dom de Einstein] traz também para o palco as responsabilidades éticas que os cientistas têm de enfrentar, provando, num contexto diferente - no caso de Fritz Haber, Albert Einstein e as duas Grandes Guerras -, que a ciência nunca é um labor isento de "contaminação". Thiessen formula a questão de apurar o que acontece quando a ciência se torna política, e quando a pesquisa cientifica é (ab)usada para propósitos militares, por outras palavras, quando a ciência descobre o pecado. E todos os três trabalhos dramáticos usam a comunidade tribal dos cientistas como um grupo exemplar para demonstrar que a"ambição sem amor"é fria.

Tanto Experiência, como 0 dom de Einstein, de Vern Thiessen, lançam novas luzes sobre a condição ambígua de "Jano bifronte" da pesquisa científica que, por um lado, pode trazer beneficios ao homem e, por outro, pode ser virada contra o próprio homem provocando destruição e "pobreza", ou um futuro que, para alguns, aparece como uma outra forma de apocalipse, como, por exemplo, uma sociedade de clones humanos. Em cada caso, os dramaturgos analisam a (auto)-imagem dos cientistas, as suas crenças e esperanças tal como as suas atitudes em relação à sua ciência e à sua responsabilidade social. Peças como Proof [Prova] e OED [Quod erat demonstrandum ${ }^{6}$ ] enfatizam os métodos idiossincráticos com que alguns cientistas, neste caso os matemáticos, agarram a realidade e tentam "calcular as probabilidades". Auburn e Parnell usam os seus cientistas ficcionais para debaterem o desamparo extremo do homem face à vida à mortalidade e à morte. Ainda que os homens em geral e os cientistas em particular tenham sempre acreditado na perfeição humana, na possibilidade de deslindarem os segredos da natureza e atingirem o controlo sobre as suas forças, esbarramos sempre com as nossas limitações e a nossa mortalidade. Mesmo a firme convicção na lógica de causa e efeito, - tão importante durante o lluminismo e tão determinante para o pensamento ocidental e os seus conceitos de progresso - revela ter limites, como tão bem notaram Auburn e Parnell, mas também Poliakoff (Blinded by the Sun [Cego pelo sol]) e Paul Mullin (Louis Slotin Sonata [Sonata Louis Slotin]. Por vezes, a "causa" não existe.

\section{História da ciência no teatro}

Uma forma especial de "peça sobre a ciência", a peça de "história da ciência no teatro" olha retrospectivamente para o tempo, os factos históricos e os cientistas reais, questiona o seu papel, bem como a sua representação e imagem nos média. Aqui destaca-se o discurso metadramático da escrita da História e as peças confrontam o passado para nos guiarem para o futuro. Um dos aspectos mais relevantes da "história da ciência no teatro" é a tentativa de os historiadores da ciência - cientistas e/ou dramaturgos - captarem a atenção de um público ou leitor para a vida de um cientista esquecido e desaparecido. Muitas histórias de vida fornecem amplo material para um teatro fascinante. Quando questionado sobre a sua motivação para escrever uma peça sobre o génio matemático Alan Turing, Hugh Whitemore explicou que residia na biografia de Tuning, uma vida extraordinária "que um ficcionista não se atreveria a inventar" e que o convencera a arriscar dramatizando os momentos-chave da vida de Tunning, embora admita conhecer muito pouco sobre a matemática (Whitemore 1987) ${ }^{7}$.

Como Robert Marc Fiedman mostra na sua fantástica peça sobre Lise Meitner, e Sidney Perkowitz no seu texto sobre Rosalind Franklin, o palco é o espaço perfeito para despertar consciências, para a reflexão crítica sobre a 


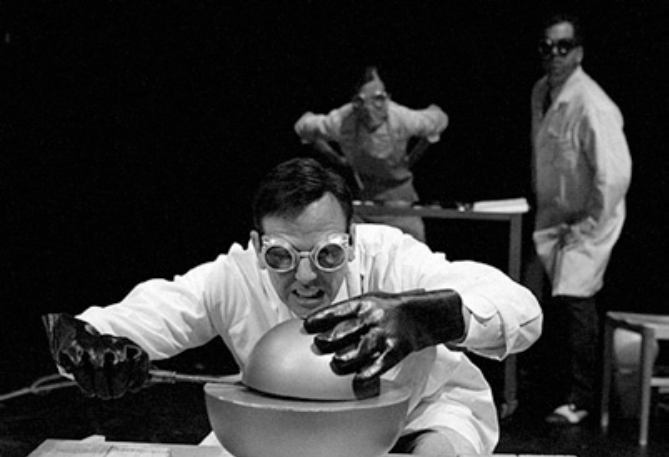

memória privada e as imagens públicas, bem como sobre os mecanismos internos da comunidade tribal daqueles cientistas e comités do Nobel, iluminando os destinos individuais e histórias de vida paradigmáticas.

Lise Meitner, devido à sua condição de judia, teve de fugir da Alemanha, deixando a sua vida científica e reputação em Berlim; e Rosalind Franklin morreu precocemente, tornando-se assim vítima do seu próprio orgulho pessoal. Estes são temas de circunstâncias políticas e de destino pessoal, de ignorância pública e de interesse privado. Pelo contrário, em peças como 0 dom de Einstein ou $Q E D$, os cientistas "reais" são parte de um discurso meta-dramático sobre a memória, a escrita da história e a historiografia que domina a problematização da cultura tribal e das responsabilidades dos cientistas, tal como do seu impacto sociopolítico e cultural.

Michael Frayn concentrou-se num momento particular do tempo: a noite em que Heisenberg visitou Bohr, em 1941. A acção dramática é determinada estrutural e tematicamente pela tentativa de apresentar diferentes versões deste facto particular, "numa constante procura de respostas para as perguntas de sempre: o que aconteceu, porquê e com que propósito?" Numa fusão engenhosa de forma e mensagem, este dramaturgo apresenta reflexões sobre a história e a historiografia, sobre a programação e apresentação pública, sobre a responsabilidade individual e colectiva, sobre a memória pessoal e a imagem pública. A questão científica da incerteza e complementaridade não está no centro do enredo, tal como a questão do seu significado simbólico; importa, antes, focar a apresentação de factos individuais integrados num discurso sobre a forma e a função historiográficas. Frayn analisa o alerta de Georg Wilhelm Friedrich Hegel de que o cerne e o significado (Kern und Sinn), de um incidente histórico deveria ser clarificado através da remoção de "peripécias secundárias e aspectos irrelevantes da acção" . Para "deixar cair as circunstâncias relativas e as idiossincrasias da personagem, e substituí-las pelas questões verdadeiramente essenciais (ESZ)" que é, em última análise, a sua tarefa por excelência ${ }^{8}$.

"Fronteiras": "Ciência para brincar" e "Ciência como uma folha de parra"

Dois subgéneros pertinentes e adicionais devem ser classificados sob a designação geral de "fronteiras". Eu chamo-Ihes "ciência para brincar" e "ciência como uma folha de parra".

"Ciência para brincar" é uma categoria que inclui Arcádia, uma peça onde a ciência é usada no seu sentido metafórico e simbólico - apresentado de forma muito

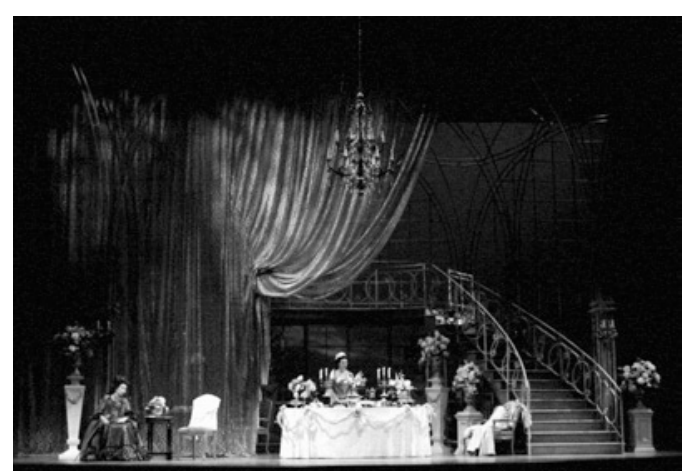

inteligente e sofisticada - dentro de um enredo, onde as questões científicas são parte de um discurso não metafórico mais abrangente. Neste sentido, Arcádia, de Tom Stoppard, parece ser única. A peça, datada de 1993 é, tal como Copenhaga de Frayn, uma das mais conhecidas "peças sobre a ciência", e provocou uma grande vaga de peças deste género, que foram definindo os seus percursos em vários palcos internacionais. Arcádia também gerou um número significativo de artigos académicos, e, levando em consideração a impressionante erudição com que muitos estudiosos trabalharam as teorias científicas na sua relação com a acção dramática e o seu consequente potencial simbólico, é bastante irónico que, de facto, a peça possa ser excluida do género dramático "peça sobre a ciência" se utilizarmos grelhas e parâmetros como os propostos por Carl Djerassi. Mesmo que concordemos, como tanto eu como ele fazemos, que não apenas as quatro condições tenham sido preenchidas ao mesmo tempo, Arcádia continua a ser um patinho feio. Muitos foram os artigos que sublinharam as questões científicas, nomeadamente a termodinâmica e a entropia, bem como o Último Teorema de Fermat, que identificamos no diálogo dramático. Contudo, elas servem apenas a função de construir uma rede inteligente e complexa de alusões simbólicas e níveis subliminares de significação. Utilizados não apenas por si mesmos, mas para compor um engenhoso "drama de ideias", a ciência é aqui, em primeiro lugar, algo a ser representado dentro de uma história de "[s]exo e literatura", "literatura e sexo".

A última categoria, "Ciência como uma folha de parra", reporta-se a peças que configuram um rebanho "ovelhas negras", na medida em que apresentam o nome de um cientista no título ou no argumento, mas a acção dramática não está centrada neles, ou não fazem um uso relevante - simbólico ou metafórico - da ciência. Estas peças podiam, portanto, ser totalmente excluídas do género "peça sobre a ciência", e esta decisão depende, claro, do recurso à "muleta" da definição do termo. Transit of Venus [Viagem de Vénus], Hawking's Dream [O sonho de Hawking] e Clever Dick [A esperteza de Dick] são bons exemplos destes casos de fronteira, trabalhos teatrais onde o conteúdo científico e o cientista estão presentes, mas onde a ciência foi marginalizada no que diz respeito ao enredo, à estrutura e ao conteúdo simbólico e o cientista é concebido para ilustrar a sua vida "real" ou a sua personalidade. Stephen Hawking, Nikole Tesla, e Richard Feynman são nomes encantadores para títulos de peças que levam as pessoas a comprar o bilhete de teatro ou o livro. Mas depois, estes cientistas famosos ou desaparecem totalmente do enredo (como em Tes/a's Letters [Cartas de Tes/a]), ou são reduzidas
Louis Slotin Sonata, de Paull Mullin, Circle $X$ Theatre, 1999, (William Salyers).

Transit of Venus, de Maureen Hunter, Manitoba Opera, 2007, (Judith Forst e Jean Stilwell), fot. R. Tinker.

${ }^{8}$ Esta caracteristica coloca desde já limites temporais ao género, uma vez que peças antigas como The Virtuoso [0 Virtuoso] (1676), de Thomas Shadwell, The Alchemist [0 alquimista] (1610), de Ben Jonson (1610), ou Doctor Faustus [Doutor Fausto] (1604 1616), de Christopher Marlowe, não tratam da ciência real, mas, no melhor dos casos, da alquimia, e essa diferença é fundamental. 
Transit of Venus, de Maureen Hunter Manitoba Theatre Centre, 2007, (Monica Huisman e Russel Braun), fot. R. Tinker.

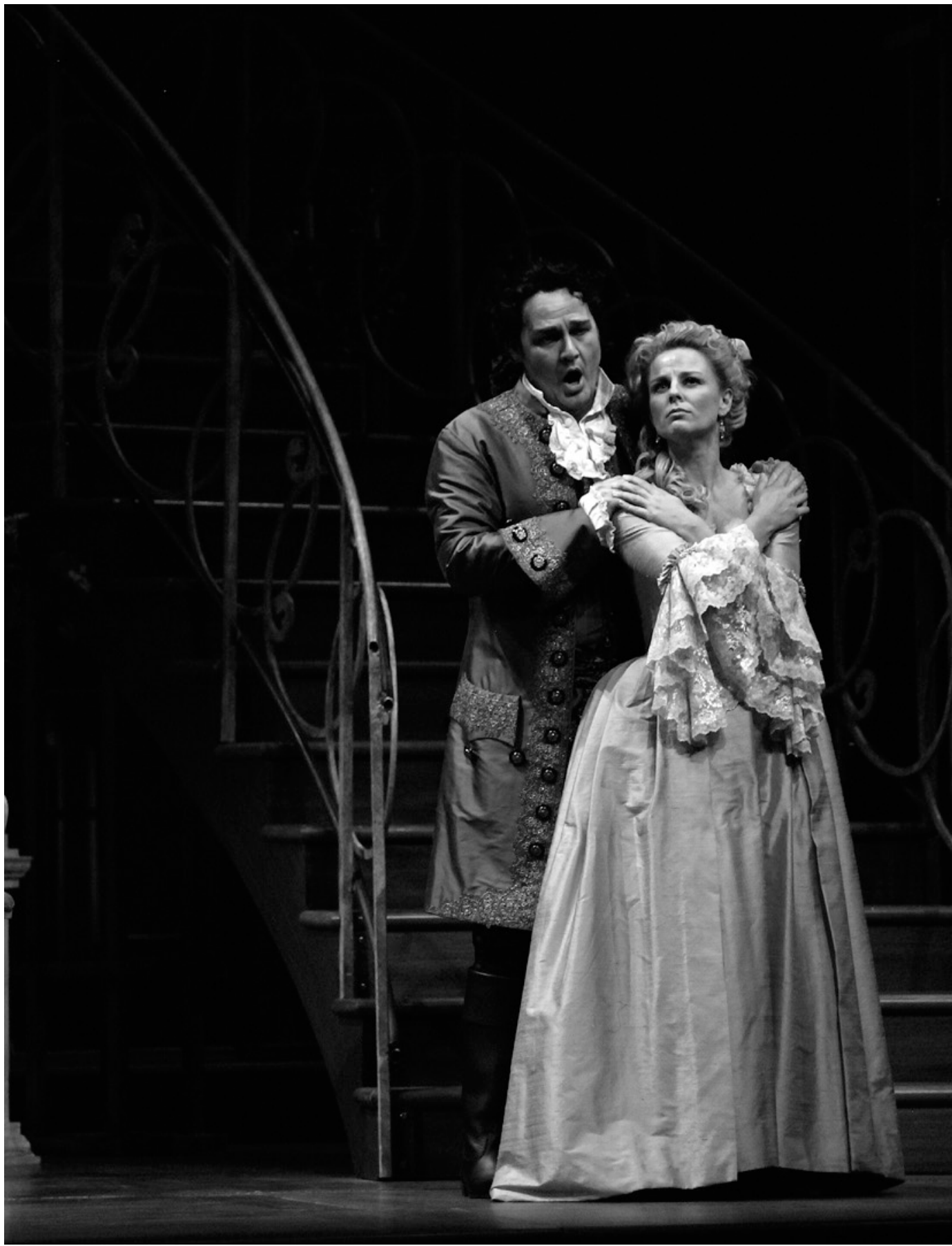

a uma personagem chamada Hawking ou Feynman. Em Viagem de Vénus, a astronomia e o desejo de traçar percurso de Vénus são justapostos ao desejo humano de amor. Maureen Hunter compõe as emoções humanas e a desolação dentro - e através de - um argumento emocionalmente controlado onde brilham Guillaume Le Gentil de la Galasière e o seu "amor paradisíaco", celeste. No caso de 0 sonho de Hawking, de Erwin Riess, o físico teórico, mundialmente conhecido, Stephen Hawking é usado como teatro de agit-prop numa obscura fusão de buracos negros, o Tatcherismo, a eutanásia e a eugenia. A esperteza de Dick, de Crispin Whittell, é uma farsa pósmoderna divertida que destrói a personagem Richard Feymann num espectáculo ligeiro ou apenas numa leitura leve. Aqui, também, não foi introduzida no enredo nenhuma lição de matemática, de forma mais ou menos encoberta, e o que foi este homem e a sua atitude matemática em relação à vida e à natureza foram convocados para uma abordagem das crenças e das desilusões dos cientistas, em particular, mas que todos, em geral, temos de enfrentar.

Nestes quatro casos, a ciência e os cientistas estão ainda presentes, de uma forma ou de outra, mas o enredo e a mensagem dirigem-se noutros sentidos. "A ciência como uma folha de parra" está, portanto, no fim do arcoíris da larga variedade de peças designadas por "peças sobre a ciência".

Toda a taxonomia constitui um modo simplista de etiquetar, uma tentativa de limar arestas entre os autodenominados grupos que são essencialmente vagos ou 
nebulosos e nunca podem deixar de ser ambíguos ou tornar-se definidos como as classificações sugerem. Como Wai Chee Dimock notou tão sucintamente "os géneros têm nomes sólidos, ontologicamente fixados. 0 que eles designam, contudo, não são classes taxonómicas de igual solidez mas campos emergentes e efémeros, definidos sistematicamente por novas entradas que ainda estão a ser produzidas" (Dimock 2007: 1379). Portanto, é perfeitamente claro que a minha tentativa de agrupar certas peças sob etiquetas auto-designadas está sujeita a críticas e pode ser refutada, dado que os textos literários são, e serão sempre, um fenómeno mutável, desafiando claramente a classificação em grupos. Eles podem partilhar um determinado conjunto de semelhanças em relação aos temas, argumentos e estratégias narrativas, mas os textos individuais agrupados relacionam-se sempre com diversos repertórios ao mesmo tempo, apresentando múltiplos aspectos que são detectáveis na prática literária (Wesseling 1991:19).

$\mathrm{Na}$ "peça sobre a ciência", as duas culturas unem-se através da compreensão da cultura como um sistema de redes cruzadas onde o palco oferece um espaço de comunicação e ligação entre vários grupos culturalmente especializados. As "peças sobre ciência" criam a polaridade ciência vs cultura ou ciência vs literatura. Elas põem em causa as diferenças entre estes dois campos de expressão cultural e de interacção, mas buscam pontos de encontro e modos de junção de forma a conseguirem a compreensão mútua e a troca frutuosa num momento em que a ciência não só entrou no mercado com um peso e extensão anteriormente desconhecidos, mas onde a pesquisa científica e o "progresso" exigem o nosso envolvimento activo, e onde nós, pelo nosso lado, procuramos mais direitos e esclarecimentos de forma a sermos capazes de tomar as nossas decisões públicas ou privadas.

\section{Referências bibliográficas}

AUBURN, David Auburn (2001), Proof, New York/London, Faber and Faber. BODMER, Walter (1985), The Public Understanding of Science, London,

$$
\text { Royal Society. }
$$

DIMOCK, Wai Chee (2007), "Introduction: Genres as Fields of Knowledge." PMLA 122.5 Special Topic: Remapping Genre (October), pp. $1377-1388 ; 1379$.

DJERASSI, Carl (2000), An Immaculate Misconception. Sex in an Age of Mechanical Reproduction, London, Imperial College.

DJERASSI, Carl / HOFFMANN, Roald (2001), Oxygen, Weinheim /New York, Wiley-Vch.
ESSLIN, Martin (1988), "'Dead! And never called me mother!': The Missing Dimension in American Drama." Studies in the Literary Imagination 21.2 (Fall), pp. 23-33.

FRAYN, Michael (1998), Copenhagen, London, Methuen FREESE, Peter / HARRIS, Charles B., Eds. (2004), Science, Technology, and the Humanities in Recent American Fiction, Essen, Blaue Eule. FRIEDMANN, Robert Marc (2004), Remembering Miss Meitner, Maio 2004. Manuscrito inédito, cortesia do autor.

GORDON, Mick / BROKS, Paul (2005), On Ego. A Theatre Essay, London, Oberon.

GREGORY, Jane / MILLER, Steve, eds. (1998), Science and the Public, New York, Plenum.

GRÜNZWEIG, Walter (2004), "Science-in-fiction: Science as Tribal Culture in the Novels of Carl Djerassi", In Freese / Harris, eds. 2004, pp. 231-248.

HODGES, Andrew (1983), Alan Turing. The Enigma, New York, Simon \& Schuster.HUNTER, Maureen (1992), Transit of Venus, Winnipeg, Blizzard.

ORTHOFER, M.A. (2002),"The scientist on the stage: a survey", Interdisciplinary Science Reviews 27.3 (Fall), pp. 173-183.

PARNELL, Peter (2003), QED, New York, DPS.

POLIAKOFF, Stephen (1996), Blinded by the Sun, London, Faber and Faber.

MULLIN, Paul (1999), Louis Slotin Sonata (Manuscrito não publicado, cortesia do autor).

PERKOWITZ, Sidney (2004), Glory Enough. A play about Rosalind Franklin and the structure of DNA (Manuscrito não publicado, cortesia do autor).

PRIEST, Susana Hornig (1995), "Information Equity, Public Understanding of Science, and the Biotechnology Debate", Journal of Communication 45.1 (March), pp. 39-54.

RIESS, Erwin (1998), Hawking's Dream (Hawkings Traum) or The Grand Unified Quantum Theory of Human Gravity (trad. Penny Black, London, Oberon, 2000).

ROCAMORA, Carol (2000), "Scientific Dramaturgy", The Nation 5, June. STANLEY, Jeffrey (1999), Tes/a's Letters, New York, Samuel French.

STEPHENSON, Shelagh 1999), Experiment With an Air Pump, London, Methuen.

STOPPARD, Tom Stoppard (1993), Arcadia, London, Faber and Faber. THIESSEN, Vern (2003), Einstein's Gift, Toronto, Playwrights Canada. WESSELING, Elisabeth (1991), Writing History As A Prophet:Postmodernist Innovations of the Historical Novel. Amsterdam: Benjamins. WHITEMORE, Hugh Whitemore (1987), Breaking the Code, London, Samuel French.

WHITTELL, Crispin (2006), Clever Dick, London, Oberon.

ZEHELEIN, Eva-Sabine (2009), Science: Dramatic. Science Plays in America and Great Britain, 1990-2007, Heidelberg, Universitätsverlag Winter. 